\title{
EFFECTIVE REPAIR OF ARTICULAR CARTILAGE USING HUMAN PLURIPOTENT STEM CELL-DERIVED TISSUE
}

\author{
O.F.W. Gardner ${ }^{1 \S}$, S.C. Juneja ${ }^{2 \S}$, H. Whetstone ${ }^{3}$, Y. Nartiss ${ }^{4}$, J.T. Sieker ${ }^{1}$, C. Veillette ${ }^{2}$, G.M. Keller ${ }^{4}$ \\ and A.M. Craft ${ }^{1,5 *}$ \\ ${ }^{1}$ Department of Orthopedic Surgery, Boston Children's Hospital, Harvard Medical School, Boston, \\ MA, USA \\ ${ }^{2}$ The Arthritis Program, Krembil Research Institute, University Health Network, Toronto, Canada \\ ${ }^{3}$ Developmental and Stem Cell Biology, Hospital for Sick Children, Toronto, Canada \\ ${ }^{4} \mathrm{McEwen}$ Centre for Regenerative Medicine, University Health Network, Toronto, Canada \\ ${ }^{5}$ Harvard Stem Cell Institute, Cambridge, USA \\ $\S$ These authors contributed equally to this work.
}

\begin{abstract}
In an effort to develop an effective source of clinically relevant cells and tissues for cartilage repair a directed differentiation method was used to generate articular chondrocytes and cartilage tissues from human embryonic stem cells (hESCs). It has previously been demonstrated that chondrocytes derived from hESCs retain a stable cartilage-forming phenotype following subcutaneous implantation in mice. In this report, the potential of hESC-derived articular-like cartilage to repair osteochondral defects created in the rat trochlea was evaluated. Articular cartilage-like tissues were generated from hESCs and implanted into the defects. After 6 and 12 weeks, the defects were evaluated histologically and immunohistochemically, and the quality of repair was assessed using a modified ICRS II scoring system. Following 6 and 12 weeks after implantation, hESC-derived cartilage tissues maintained their proteoglycan and type II collagen-rich matrix and scored significantly higher than control defects, which had been filled with fibrin glue alone. Implants were found to be well integrated with native host tissue at the basal and lateral surfaces, although implanted human cells and host cells remained regionally separated. A subset of implants underwent a process of remodeling similar to endochondral ossification, suggesting the potential for a single cartilaginous implant to promote the generation of new subchondral bone in addition to repair of the articular cartilage. The ability to create cartilage tissues with integrative and reparative properties from an unlimited and robust cell source represents a significant advance for cartilage repair that can be further developed in large animal models before clinicalsetting application.
\end{abstract}

Keywords: Cartilage - repair/regeneration, cells/tissues - cartilage, stem cells - chondrogenesis, stem cells - differentiation, tissue engineering / regenerative medicine, translational and preclinical research.

*Address for correspondence: April M. Craft, PhD, Department of Orthopedic Surgery, Boston Children's Hospital, Enders 260, Mailstop 3096, 300 Longwood Avenue, Boston, MA 02115, USA.

Telephone: +1 (617) 919-4495 Email: april.craft@childrens.harvard.edu

Copyright policy: This article is distributed in accordance with Creative Commons Attribution Licence (http://creativecommons.org/licenses/by-sa/4.0/).

\section{Introduction}

Damage to the articular cartilage often leads to the development of joint degeneration, or osteoarthritis, which causes lifelong pain and restricts the ability of patients to lead normal lives. Current treatments for damaged or degenerating cartilage are inadequate, primarily focusing on pain management and joint replacement (Redman et al., 2005). Successfully repairing damaged areas of articular cartilage using human pluripotent stem cell-based therapies may provide an effective way of preventing or delaying the onset of joint degeneration and improving quality of life for patients.

Current cell-based therapies approved for cartilage repair are limited to autologous chondrocyte implantation (ACI) and its modified form, matrixinduced autologous chondrocyte implantation (MACI) (Brittberg, 2010; Brittberg et al., 1994). These procedures require an initial operation to collect small pieces of cartilage, from which chondrocytes can be isolated and expanded before the re-implantation of the cultured cells during a second procedure. ACI and MACI, while moderately successful, have a number 
of disadvantages such as the requirement for multiple surgical procedures, donor site morbidity (LaPrade and Botker, 2004; Matricali et al., 2010), the low numbers of cells retrieved, and the dedifferentiation of chondrocytes during expansion (Benya and Shaffer, 1982; Holtzer et al., 1960; von der Mark et al., 1977). In addition, the efficacy of such technologies has not surpassed that of the current standard of care, microfracture, which involves perforating the subchondral bone, releasing cells from the bone marrow cavity to stimulate repair within the defect (Steadman et al., 2001). All of these approaches result in fibrocartilage-like repair tissue that lacks important biochemical and biomechanical properties of cartilage (LaPrade et al., 2008), which can lead to graft delamination and failure.

Human pluripotent stem cells (hPSCs) may provide solutions to many of the problems currently faced in treating damaged articular cartilage. The use of self-renewing human embryonic stem cells (hESCs) provides an opportunity to develop an 'off the shelf' cell source and/or tissue implant for cartilage repair without the need for the multiple procedures currently required for cell-based therapies. Further, a cartilage defect could be repaired using tissue generated from induced pluripotent stem cells (hiPSCs) derived from a patient's own cells, thus reducing the potential for immune rejection (Staerk et al., 2010; Takahashi et al., 2007). Although rigorous safety studies are required before the routine clinical use of iPSCs, many approaches to treat human disease using these cells are under development. Regenerative-medicinebased biotechnology companies and academic institutions are developing clinical grade iPSCs, and the first clinical trial for iPSC-derived platelets was approved in Japan in 2018 (Akabayashi et al., 2019). Clinical trials are also ongoing to establish the potential for hESC-derived progenitor cells to treat a number of conditions including ischemic heart disease and age-related macular degeneration (Ilic et al., 2015). The progression of these studies clearly demonstrates the need, and also the potential, for hPSC s to be used in the clinic in the near future.

Previous work has shown that both hESC and hiPSCs can be differentiated into either an articularlike or a hypertrophic, growth plate-like chondrocyte phenotype using chemically defined and precisely controlled directed differentiation methods (Craft et al., 2013; Craft et al., 2015). This protocol provides the signaling that embryonic cells would experience during cartilage development in utero, and involves the induction of a primitive-streak-like mesoderm followed by specification of the chondrogenic mesoderm and finally the generation of chondrocyte progenitors. Long term exposure to transforming growth factor $\beta 3$ (TGF $\beta 3$ ) further induces the formation of an articular cartilage-like tissue, marked by the expression of SOX9, COL2A1 and PRG4, the latter encoding the proteoglycan lubricin, which is important for maintaining a frictionless articular surface. Conversely, the exposure of chondrocyte progenitors to bone morphogenetic protein 4 (BMP4) induces the expression of hypertrophic chondrocyte genes including COL10A1 and ALPL. The same work also showed that when implanted subcutaneously into a mouse, TGF $\beta 3$-treated chondrocytes produced articular-cartilage-like matrix that resisted vascularization and ossification over a period of 12 weeks in vivo, whilst tissue produced by the hypertrophic BMP4-treated chondrocytes created a cartilaginous matrix that initiated remodeling and ossification (Craft et al., 2015). The capability of TGF $\beta 3$-treated hESCs to generate phenotypically stable chondrocytes represents a significant step forward in developing new approaches for the surgical repair of articular cartilage.

In addition to hPSCs, other cellular sources are being investigated for use in cell-based therapies, in particular human mesenchymal stem cells (hMSCs). Human MSCs can be isolated from a number of post-natal tissues including adipose, synovial membrane, periosteum and bone marrow and are also capable of generating cartilage-like tissue when stimulated with TGF $\beta$ (De Bari et al., 2001a; De Bari et al., 2001b; Johnstone et al., 1998; Pittenger et al., 1999; Zuk et al., 2002). However, unlike hESCs and hiPSCs, hMSCs demonstrate high levels of donor-todonor variability (Stoddart et al., 2012) and are not capable of maintaining a stable articular-cartilagelike phenotype in vivo. Instead these cells progress towards hypertrophy in response to chondrogenic induction (Johnstone et al., 1998; Mueller et al., 2013). The relative homogeneity and phenotypic stability of hPSC-derived chondrocytes compared to hMSCs (Craft et al., 2015), in conjunction with their unlimited capacity for proliferation makes them an excellent candidate cell type for future cell-based therapies.

Alongside research focused on mesenchymal stem cells (MSCs), different populations of cells within cartilage itself are of interest for repair. Dowthwaite et al. (2004) identified a population of chondroprogenitor cells (CPCs) in the surface layer of articular cartilage capable of undergoing trilineage differentiation. Further work has shown that CPCs can be isolated from the articular and auricular cartilage of a number of species and are less prone to entering into terminal differentiation than MSCs (Kobayashi et al., 2011; Levato et al., 2017; McCarthy et al., 2012; Williams et al., 2010). Another cartilage population under investigation are nasal chondrocytes (Pelttari et al., 2014). Nasal cartilage is neural crest-derived and unlike mesoderm-derived articular chondrocytes, nasal chondrocytes (NCs) do not express HOX genes. However, NCs have the ability to acquire a HOX profile of typical ACs after implantation into a chondral defect (Pelttari et al., 2014). Initial in vivo work in goats and a first in human trial demonstrated the ability of these cells to generate stabile cartilage in chondral defects (Mumme et al., 2016a; Mumme et al., 2016b). Despite the tremendous advances that have been made, the use of adult cells still requires multiple operations, 
whereas hPSCs have the potential to be used in an 'off the shelf' fashion.

The aim of the present study was to investigate the use of hESC-derived tissue to repair damaged articular cartilage in vivo. To conduct this study, size-matched biopsy punches of hESC-derived articular-cartilage-like tissues were implanted into osteochondral defects created in the trochlear groove of athymic nude rat knee joints. The resulting repair tissue was compared histologically and immunohistochemically to defects filled with fibrin glue alone at both 6- and 12-weeks post implantation.

\section{Materials and Methods}

\section{Cell culture}

Human ESC derived articular-like cartilage tissues were generated as described previously (Craft et al., 2015) using the HES2-RFP hESC line, which was engineered to constitutively express the red fluorescent protein (RFP) (Irion et al., 2007), in order to easily identify human cells following implantation. This directed differentiation protocol is highly reproducible and has been successfully used to generate both molecularly and histologically similar articular-like cartilage tissues from at least 5 independent hESC lines and 5 iPSC lines (Craft et al., 2015 and unpublished). Briefly, HES2-RFP hESCs were maintained on irradiated mouse embryonic fibroblasts in knock-out serum based hESC media. Embryoid bodies were formed by culturing small aggregates of feeder-depleted hESCs in StemPro-34 media (Invitrogen, Carlsbad, CA, USA) containing BMP4 (0.5 ng/mL). $24 \mathrm{~h}$ after formation, embryoid bodies were collected and resuspended in primitive streak/early mesoderm differentiation medium, consisting of StemPro-34 supplemented with bFGF (5 ng/mL), Activin A (2 ng/mL) and BMP4 (3 ng/mL, R\&D Systems, Minneapolis, MN, USA).

On day 3, embryoid bodies were collected, dissociated and plated as monolayers (500,000 cells/mL) in 96-well tissue culture plates (Falcon, Thermofisher Scientific, Waltham, MA, USA) in StemPro-34 supplemented with the inhibitor of type I activin receptor-like kinase (ALK) receptors SB431542 (5.4 $\mu \mathrm{M}$, Sigma, St. Louis, MO, USA), bFGF (20 ng/mL) and the BMPR inhibitor Dorsomorphin ( $4 \mu \mathrm{M}$, Sigma). After $48 \mathrm{~h}$ the medium was removed and maintained in StemPro-34 supplemented with bFGF (20 ng/mL) until day 15. Differentiation cultures were maintained in $5 \% \mathrm{CO}_{2}, 5 \% \mathrm{O}_{2}$ for $12 \mathrm{~d}$, then transferred to $5 \% \mathrm{CO}_{2}$ for the remainder of the culture period.

Cartilage tissues were generated from cells on day 15 of differentiation using a micromass format. Cells were dissociated from monolayer cultures and seeded into micromasses, each containing 225,000 cells. Micromass tissues were maintained for 12 to 15 weeks in high-glucose DMEM supplemented with 1× ITS supplement (Gibco, Thermofisher Scientific,
Waltham, MA, USA), ascorbic acid (50 $\mu \mathrm{g} / \mathrm{mL}$, Sigma), proline $(40 \mu \mathrm{g} / \mathrm{mL}$, Sigma) and dexamethasone (0.1 $\mu \mathrm{M}$, Sigma) and TGF 33 (10 ng/mL, R\&D Systems). The expected presence of proteoglycans and type II collagen, and lack of hypertrophic chondrocyte-like phenotypes, within the cartilaginous matrix was confirmed by histology prior to implantation.

\section{Surgical procedure}

All animal studies were approved by the Animal Resources Committee at University Health Network, Toronto, Canada. Homozygous athymic nude rats (NIH nude rats, Crl:NIH-Foxn1rnu; rnu/rnu) were purchased from Charles River Laboratories and were provided with sterile housing. Surgeries were conducted on rats between 8 and 9 weeks of age. Animals were anesthetized under $5 \%$ isoflurane (Provided by the Animal Resources Centre, University Health Network, Toronto, ON, Canada) and maintained at $2 \%$ isoflurane during surgery. Buprenorphine $(0.03 \mathrm{mg} / \mathrm{kg}$, Sigma) was used as an analgesic drug. Pre-operative and post-operative care was provided to animals according to the protocol.

The right knee area was shaved and cleaned with iodine surgical scrub (7.5\% iodine), $70 \%$ isopropanol and $10 \%$ Providone iodine (equivalent to $1 \%$ iodine) in sequence. A longitudinal incision was made on the anterior aspect of knee with a surgical scalpel blade (no.15) to expose the knee joint. The skin at medial and lateral side of knee joint was dislodged from the muscle layer using two backward strokes with a pair of surgical scissors. A second cut was made on the knee joint medially on the muscle layer. The muscle layer along with the quadriceps tendon and patella was pushed laterally to expose trochlear region of femur. Two osteochondral defects $(0.5 \mathrm{~mm}$ apart, one proximal, one distal) were created in the femoral trochlear groove with the help of a biopsy punch (1.45 mm diameter, Fine Scientific Tools, Inc., North Vancouver, BC, Canada). All defects were created by the same individual using a biopsy punch at a similar force and an angle that was perpendicular to the trochlear surface, and care was taken such that defects did not completely puncture the subchondral bone. The cartilage plug was removed from the defect with a biopsy punch, and visible blood seepage indicated that the surface of the subchondral bone layer had been reached. In cases where cartilaginous tissue remained in the defect, the remaining cartilage was debrided with the sharp end of beveled needle prior to treatment. Animals were assigned at random to the experimental (implant) or control group. Size matched biopsy punches of hESC-derived cartilage tissue were press-fitted into defects with the help of sterile cotton gauze, and then sealed with fibrin glue (TISSEEL, Baxter). Control defects were filled with fibrin glue alone. A total of 26 control defects were created in 13 knees, hESC-derived cartilage tissue was implanted into 40 defects in 20 knees.

After implantation, the muscle layer was reverted back to the medial side and quadriceps tendon 
along with the patella were placed in their original position. The medial muscle layer was sutured discontinuously at three points with 5-0 Polysorb ${ }^{\mathrm{TM}}$ suture (Covidien, Dublin, Ireland). The skin was closed using intradermal continuous suturing using 5-0 MONOCRYL suture (Ethicon, Cincinnati, $\mathrm{OH}$, USA), and glued with a thin layer of Vetbond tissue adhesive (3M). Following surgery animals were permitted to move freely, animals were monitored according to the approved animal protocol and were euthanized after 6 or 12 additional weeks.

\section{Histology and immunohistochemistry}

Immediately following euthanasia, knee joints were excised and the defects were exposed and imaged macroscopically. Whole joints were then fixed in $10 \%$ neutral buffered formalin (Sigma) and decalcified for approximately $10 \mathrm{~d}$ in Immunocal formic acid bone decalcifier solution (Decal Chemical Corp., Tallman, NY, USA). Decalcification solution was changed every $3 \mathrm{~d}$ before joints were processed for paraffin-wax embedding and histological analyses. Sagittal sections ( $5 \mu \mathrm{m}$ thickness) of defect containing trochlear grooves were stained with $0.1 \%$ safranin $\mathrm{O}$ and counterstained with Weigert's hematoxylin and $0.02 \%$ fast green, or picrosirius red for polarized light microscopy (Electron Microscopy Sciences, Hatfield, PA, USA). Immunohistochemistry was used to visualize type I (clone COL-1, Sigma), II (clone 6B3, EMD Millipore, Burlington, MA, USA) and X collagen (clone X53, Quartett, Berlin, Germany) as well as red fluorescent protein (ab34771, Abcam, Cambridge, UK). The M.o.M ${ }^{\mathrm{TM}}$ (Mouse on Mouse) Detection Kit (Vector Laboratories Inc., Burlingame, CA, USA) was used with the type I and type II collagen monoclonal antibodies to minimize background staining. Detection was performed using VECTASTAIN $\mathrm{ABC}$ and $\mathrm{DAB}$ reagents (Vector Laboratories Inc.) and sections were counterstained with Mayer's hematoxylin (Electron Microscopy Sciences). Images were acquired using a Nikon Eclipse 80i microscope and a Nikon Digital Sight DS-Ri1 camera.

\section{Histological scoring \& statistical analysis}

The quality of repair tissue in defects was determined using a modified ICRS II scoring system (MainilVarlet et al., 2010): the tissue morphology and tidemark formation parameters were removed and the middle/deep zone assessment was performed on brightfield microscopy images. Representative safranin O-stained sections of each defect were randomized and scored by three independent, blinded individuals. Each defect was scored for matrix staining, cell morphology, chondrocyte clustering, surface architecture, basal integration, subchondral bone abnormalities/marrow fibrosis, inflammation, abnormal calcification/ossification, vascularization, surface/superficial assessment, mid/ deep zone assessment, integration with surrounding cartilage, degeneration of surrounding cartilage and overall assessment. Each parameter was scored from
0 (poor repair) to 100 (normal articular cartilage).

For each of the microscopic parameters assessed, the scores from 3 blinded reviewers were averaged for each defect and plotted per treatment and time point. Successfully implanted defects (i.e., those in which human cells were identified at the time of analysis) were directly compared to defects that were treated with fibrin glue alone (unimplanted).

Analysis of each microscopic outcome measure was conducted using the Mann-Whitney U-test to compare defects containing human cells (referred to as implanted) to those that did not receive implants (unimplanted) at each time point, and to compare implanted or unimplanted defects over time. Data were also analyzed using a linear-mixed model approach to account for any covariance in defects within the same rat. There was no difference in the conclusions between the linear-mixed model analysis and the non-parametric subgroup analysis. The results from the nonparametric analyses alone are presented here. $p$-values were corrected using the Benjamini and Hochberg correction within each subgroup to control for multiple comparisons (Benjamini and Hochberg, 1995). All tests were twosided and $p$-values less than 0.05 were considered significant. Box plots were generated using Prism (GraphPad).

\section{Results}

\section{Pre-implantation tissue phenotype and surgical method}

Using serum-free directed differentiation methods previously described (Craft et al., 2015), articular cartilage-like tissues were generated from the HES2-RFP hESC line. Pre-implantation cartilage tissues resembled hyaline cartilage and consisted of chondrocyte-like cells embedded in extracellular matrix rich in glycosaminoglycans and type II collagen (Fig. 1a-b), but negative for type $\mathrm{X}$ collagen (Fig. 1c). Two osteochondral defects $(1.45 \mathrm{~mm}$ diameter) were generated in the trochlear groove of the rat femur (Fig. 1e and f), and size-matched biopsy punches of hESC-derived tissue were press-fitted into the defects. Implants were then sealed with a thin layer of fibrin glue. Six and 12 weeks later, graft retention was assessed (examples of macroscopic images following harvest are shown in Fig. 1g-h), and cartilage quality was compared to control defects treated with fibrin glue alone.

\section{Implant retention}

The use of a hESC line that constitutively expressed RFP allowed for the identification of implanted cells within defects immunohistochemically after harvest and histological processing (Fig. 1d) (Irion et al., 2007). RFP-expressing hESC-derived cells were detected in 11 of the 22 defects harvested 6 weeks post-implantation and 6 of the 18 defects analyzed at 12 weeks. The absence of detectable human 


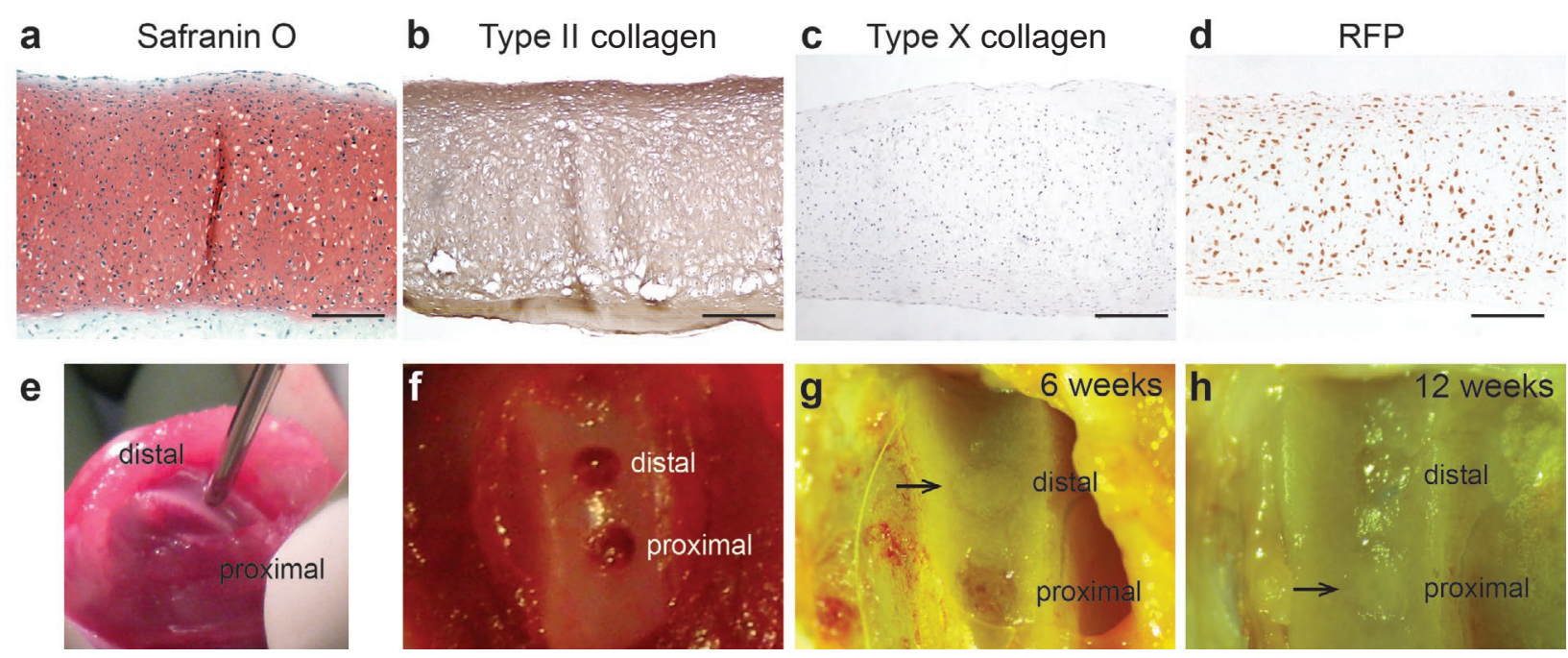

Fig. 1. Characterization of hESC-derived cartilage tissue prior to implantation, the creation of osteochondral defects, and macroscopic images of defects after 6 and 12 weeks. (a-d) Pre-implantation cartilaginous tissue derived from the HES2-RFP hESC line stains positively with safranin O (indicating the presence of GAGs), type II collagen and RFP, but not type X collagen. Scale bars $=200 \mu \mathrm{m}$. (e-f) Two $1.45 \mathrm{~mm}$ defects were created approximately $0.5 \mathrm{~mm}$ apart in the femoral trochlea groove of the right knees of athymic nude rats. (g-h) Macroscopic images of defects that were implanted with hESC-derived tissue after 6 (g) or 12 weeks (h), arrows indicate defects in which human tissue was identified histologically.

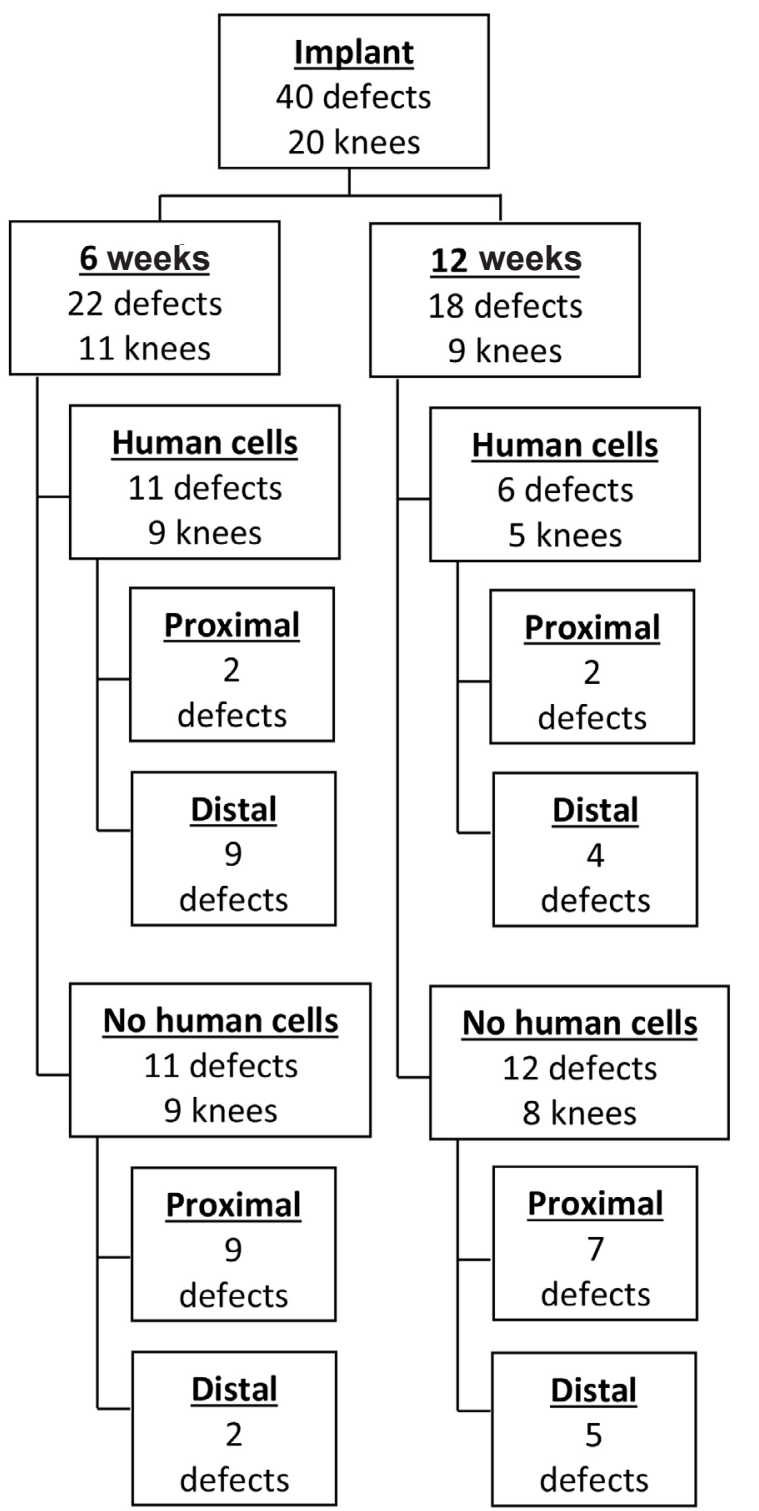

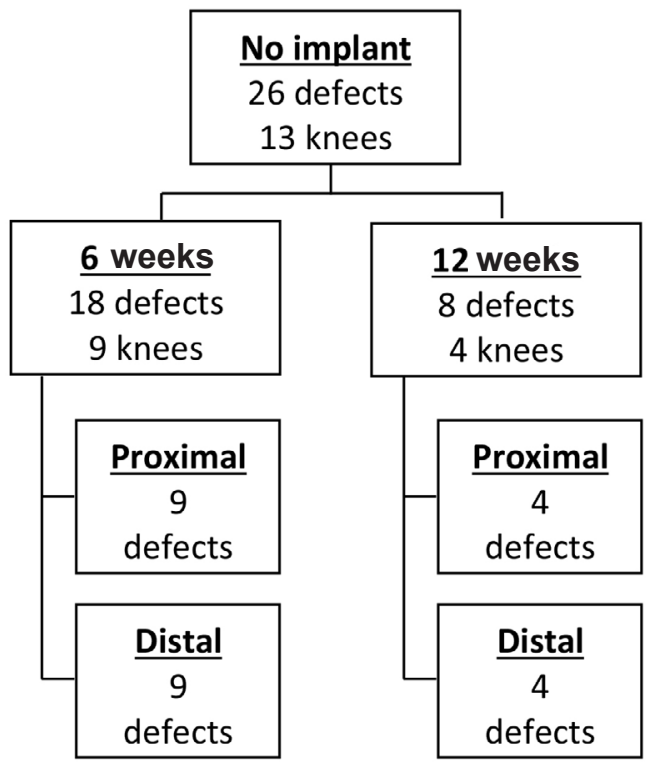

Fig. 2. Organizational chart showing the numbers of defects implanted and analyzed at 6- and 12-week time points. Defects that received human tissue ('Implant,' left) and unimplanted defects receiving only fibrin glue ('No implant,' right) are subdivided into the total number of defects created and treated at each time point ('6 weeks' or '12 weeks'). Within the 'Implant' group, the number of defects that contained human cells at the point of harvest (labelled 'Human cells') or that did not contain human cells at the point of harvest ('No human cells') is indicated. Finally, the location of the defects containing or not containing human cells (proximal or distal) is indicated. 
tissue within defects is likely due to delamination of the implanted tissue. A flowchart illustrating the number of defects analyzed at each time point is provided in Fig. 2. Interestingly, $70 \%$ of the delaminated defects were proximal and $30 \%$ were distal, indicating that proximal defects were 7 times more likely to delaminate compared to distal defects (odds ratio $=7.4 ; 95 \%$ confidence interval $=1.8-31.0$; $p=0.006)$. To precisely evaluate the level of cartilage repair resulting from implantation of hESC-derived cartilage, only defects containing human tissue, and the unimplanted control defects, were taken for further analyses.

Evaluation of cartilage matrix composition within implanted and control defects

Six weeks after implantation, strong and uniform safranin $\mathrm{O}$ staining was present in all of the defects that contained human tissue, indicating the maintenance of a glycosaminoglycan (GAG) rich matrix (Fig. 3a). Immunohistochemical labelling also indicated high levels of type II collagen (Fig. 3c). At this time point, collagen type I was not detected in areas rich in GAGs but was present at the edge of tissues and in the host derived fibrous tissue that covered the majority of implants (Fig. 3e). Control defects, filled with fibrin glue alone, contained fibrous tissue after 6 weeks that contained little to no GAGs (Fig. 3b). Immunohistochemical labelling showed an abundance of type I collagen and low levels of type II collagen present within the fibrous repair tissue (Fig. $3 \mathbf{d}$ and $\mathbf{f}$ ).

Proteoglycan-rich tissue that stained positively for type II collagen was also detected after 12 weeks in all the defects that contained human tissue (Fig. $3 \mathbf{i}$ and $\mathbf{k})$. While type I collagen was also present at
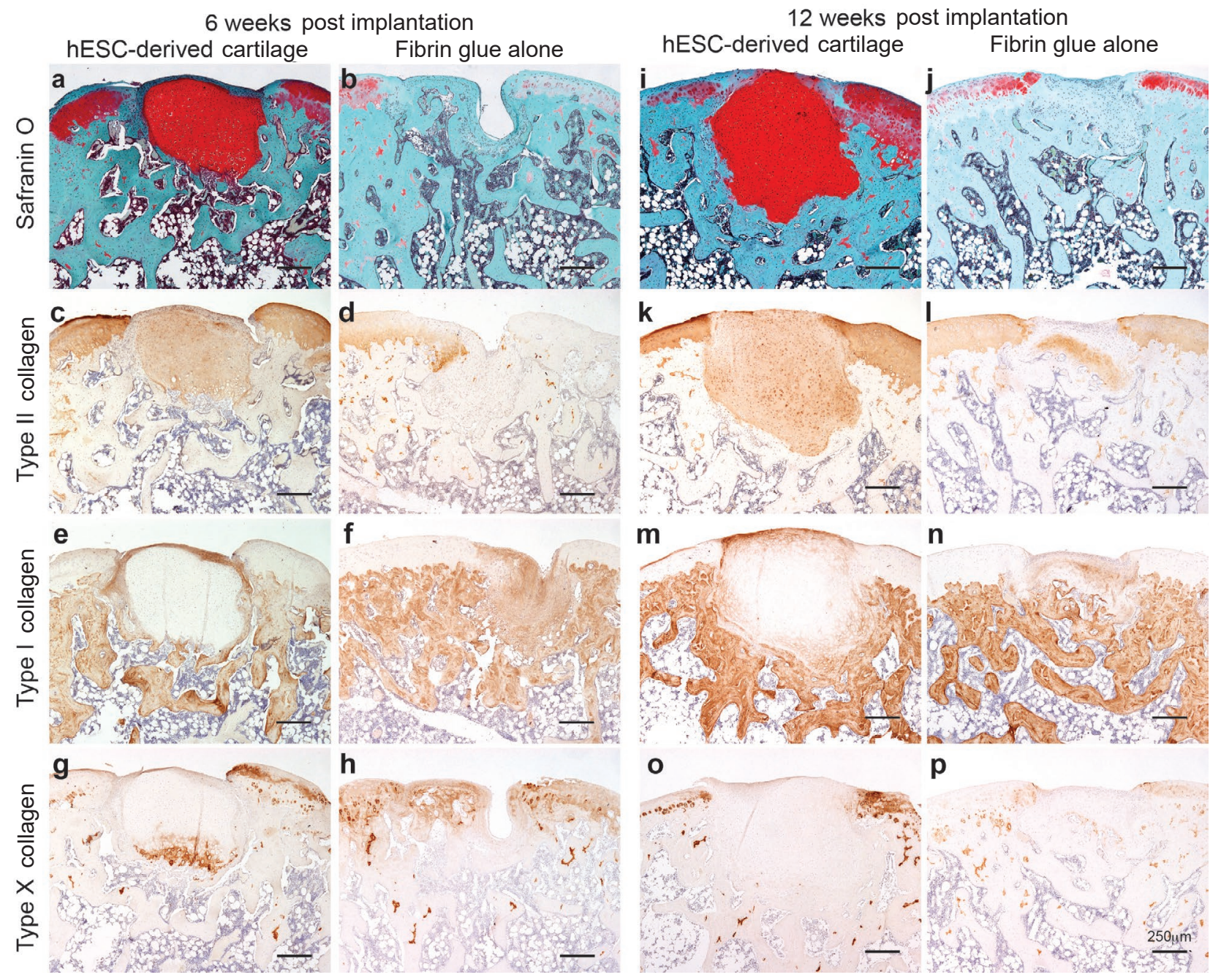

Fig. 3. Histological and immunohistochemical analysis of cartilage matrix components following implantation of hESC-derived articular cartilage tissues into osteochondral defects. Representative images of safranin O staining of proteoglycans $(\mathbf{a}, \mathbf{b}, \mathbf{i}, \mathbf{j})$ and immunohistochemical labelling of type II collagen $(\mathbf{c}, \mathbf{d}, \mathbf{k}, \mathbf{l})$, type I collagen $(\mathbf{e}, \mathbf{f}, \mathbf{m}, \mathbf{n})$ and type $X$ collagen $(\mathbf{g}, \mathbf{h}, \mathbf{o}, \mathbf{p})$ showed maintenance of cartilaginous matrix in defects that received human tissue at both $6(\mathbf{a}-\mathbf{h})$ and 12 weeks (i-p) post implantation. In contrast, control defects contain fibrous tissue at both time points $(\mathbf{b}, \mathbf{d}, \mathbf{f}, \mathbf{h}, \mathbf{j}, \mathbf{l}, \mathbf{n}, \mathbf{p})$. Scale bar $=250 \mu \mathrm{m}$. 


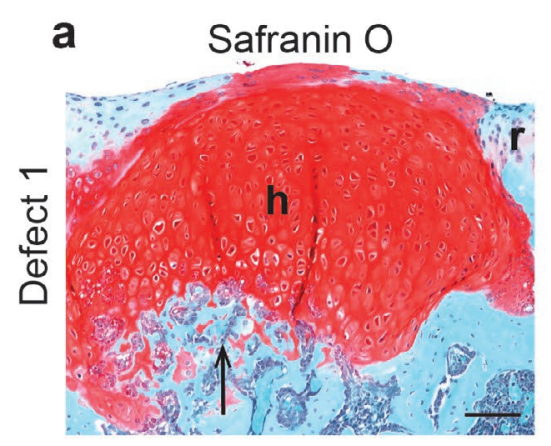

b Type II collagen

C RFP (human cells)

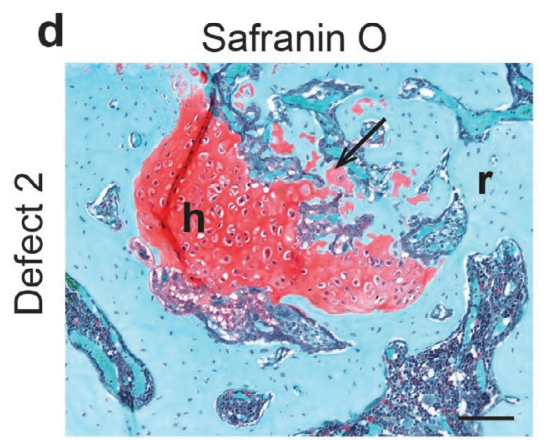

e Type II collagen
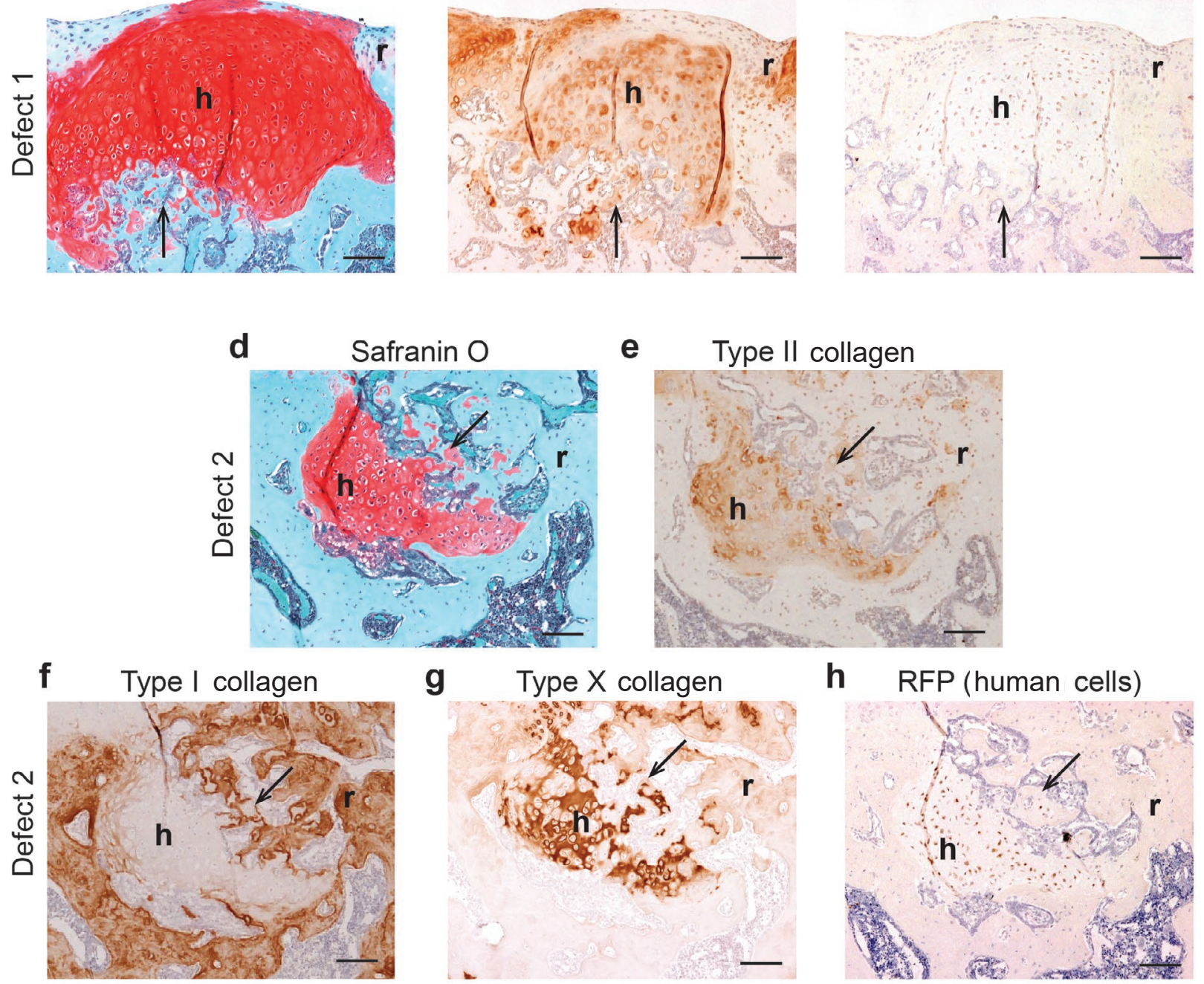

g Type $X$ collagen
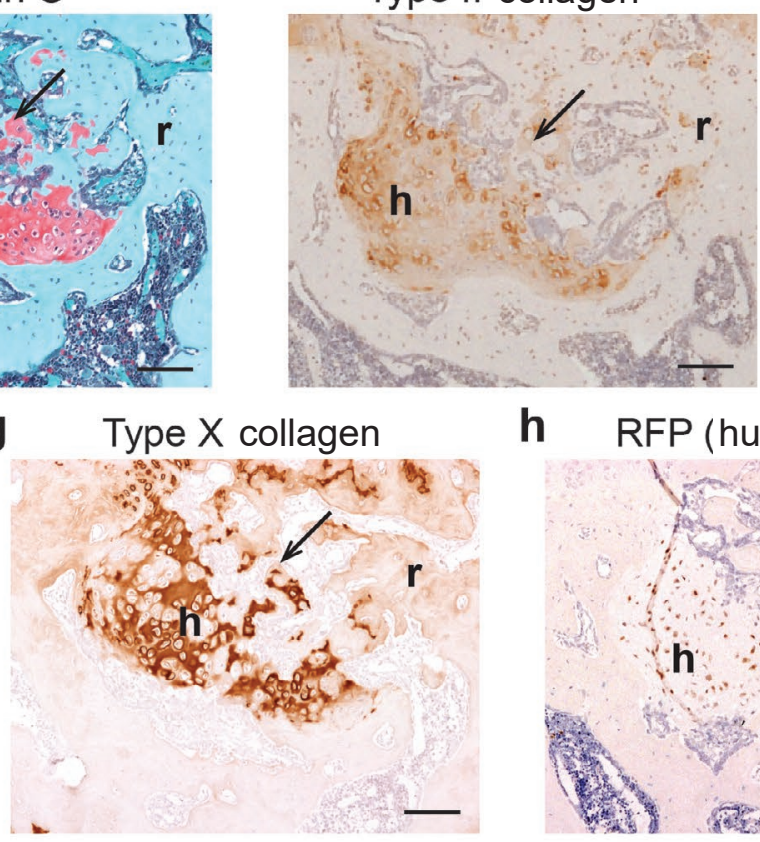

h RFP (human cells)
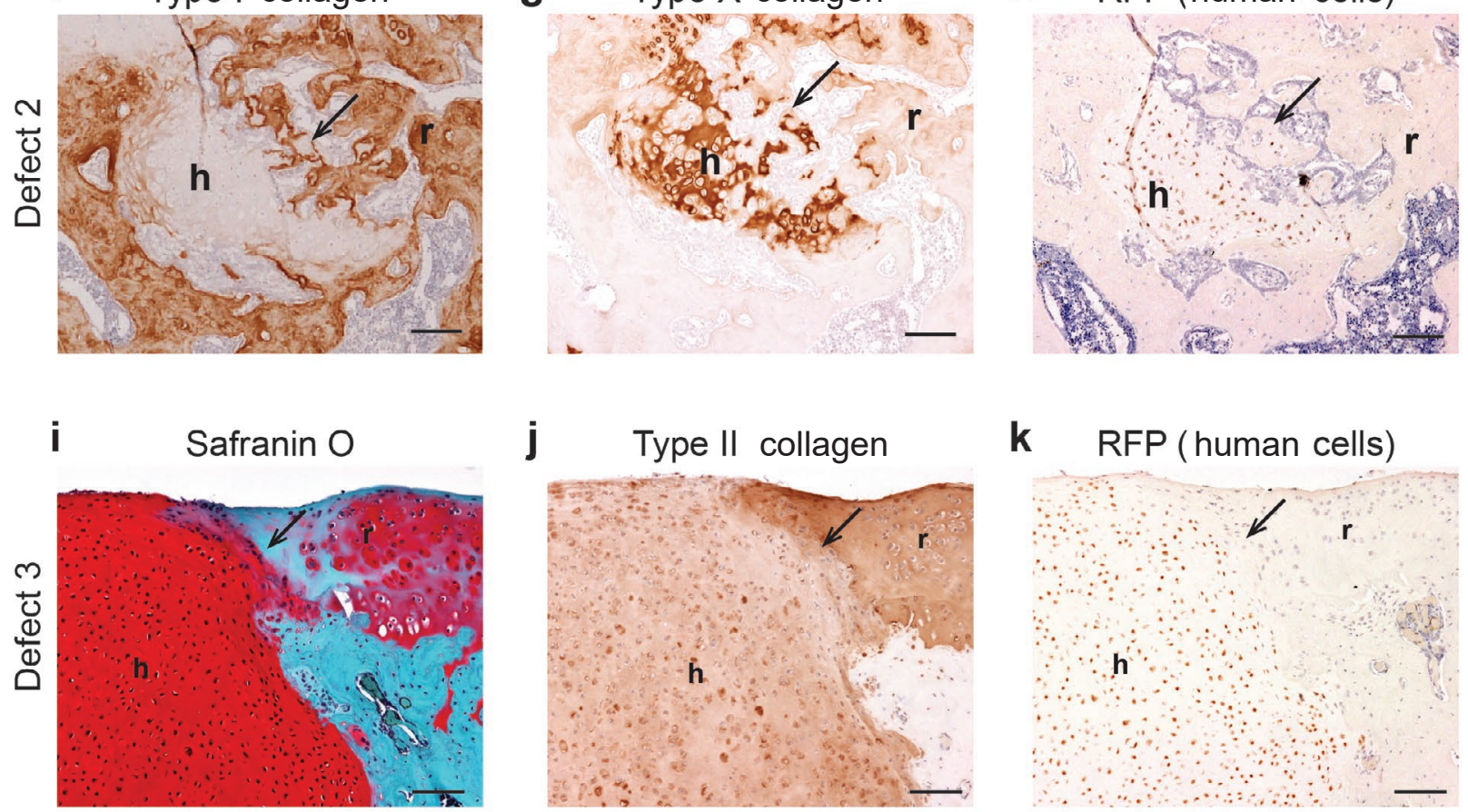

k RFP (human cells)

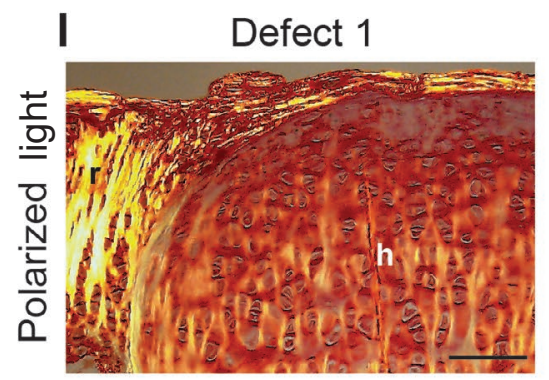

m

Defect 3

n
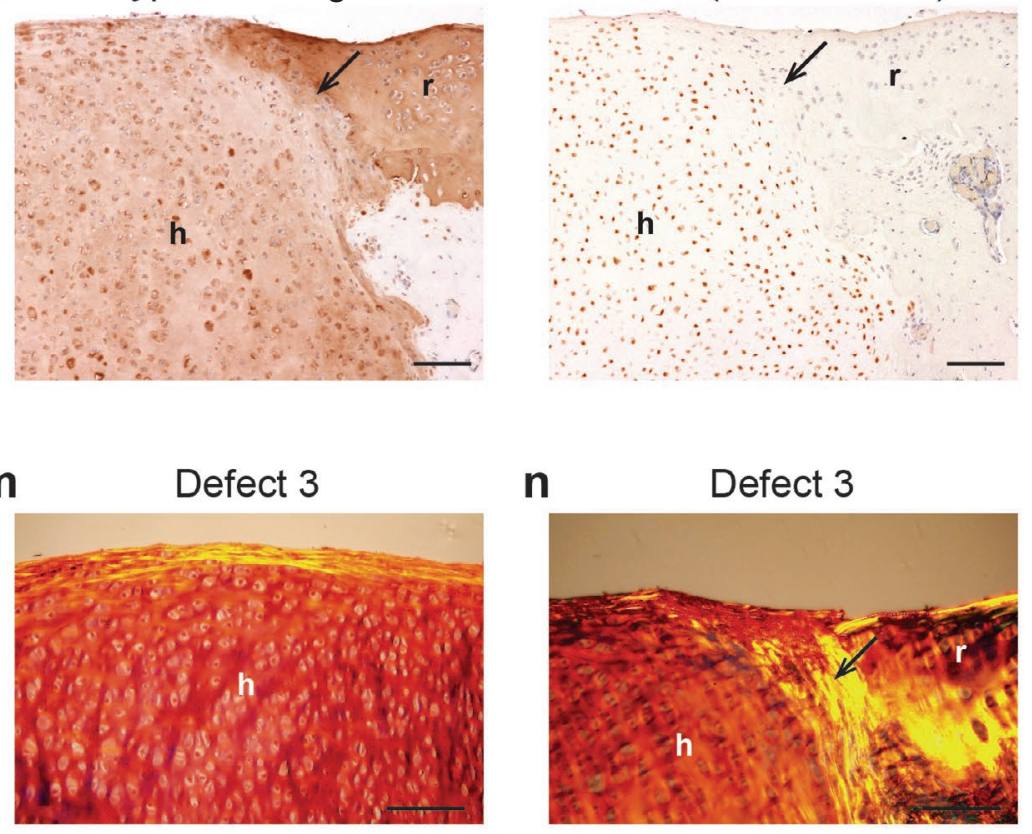
Fig. 4 (previous page). Histological and immunohistochemical evidence of remodeling and integration of hESC-derived cartilage implants in the rat knee. Three representative defects are shown from 2 different animals at 6 weeks post-implantation (Defect 1 and Defect 2) and one animal at 12 weeks post-implantation (Defect 3). hESC-derived cartilage implants stained positively with safranin O (a,d,i), type II collagen (b,e,j), and RFP (c,h,k). Defect 1 (a-c) shows the cartilage implant congruent with the native rat cartilage at the articular surface. In Defect 2, the implant is encased within subchondral bone (d-h). Type I collagen (f) was detected in bone matrix directly adjacent to the human tissue, while human cells (RFP-positive, h) were identified only within the cartilaginous region marked by type II (e) and/or type X collagen (g). Arrows in panels a-h indicate the likely direction of remodeling. The hESC-derived cartilage tissue in Defect 3 was found to be integrated basally and laterally, remained congruent with the articular surface, and showed no signs of remodeling (i-k). The presence and orientation of collagen fibrils at the articular surface of Defects 1 and $3(\mathbf{l}-\mathbf{m})$ and the integration site of Defect $3(\mathbf{n})$ was visualized by picrosirius red staining and polarized light microscopy. Collagen orientation at the superficial layer of the implants is parallel with the articular surface (l-m), while orientation is perpendicular to the surface in the deeper layers of human cartilage implanted within Defect 1 (1). Collagen fibrils are present between the hESC-derived cartilage implant and the native rat cartilage and are oriented perpendicular to the articular surface (n), concomitant with uninterrupted type II collagen staining (j). Arrows in $\mathbf{i}-\mathbf{k}$ and $\mathbf{n}$ indicate areas of lateral integration between implant (RFPpositive, k) and rat cells. Scale bar $=50 \mu \mathrm{m}(\mathbf{a}-\mathbf{k})$ or $100 \mu \mathrm{m}(\mathbf{l}-\mathbf{n}) ;$ ' $\mathrm{h}$ ' within panels indicates human tissue/ cells, 'r' indicates rat tissue/cells.

the 12-week timepoint, it did not pervade the tissue, instead it radiated in from the edges of the implants (Fig. 3m). No safranin O staining was detectable in control defects at this later time point (Fig. 3j); however, type I collagen and low levels of type II collagen persisted in the control defects at 12 weeks post-implantation (Fig. 31 and $\mathbf{n}$ ).

Implanted human tissue was found to be well integrated both basally and laterally with host tissue at both 6- and 12-weeks post-implantation (Fig. 4). Despite the continuity of matrix between the implant and the host, the distribution of human RFP-labelled cells and non-labelled host cells were clearly separate (Fig. 4c, $\mathbf{h}$ and $\mathbf{k}$ ).

Collagen type $X$ was detected immunohistochemically in 5 of 11 human tissue-containing defects at 6 weeks post implantation and one out of 6 defects at the 12-week time point (Fig. 3g, Fig. $4 \mathbf{g}$ ). In all cases the highest levels of collagen $X$ were detected along one edge of the implant, which was directly in contact with the marrow cavity. Areas adjacent to the regions containing high levels of collagen type X (Fig. 4g) contained large numbers of host-derived cells stained with hematoxylin, but not RFP (Fig. 4h). Human cells within type X collagenrich regions appeared to be undergoing hypertrophic changes, with increased cell and lacunae size, and increased alignment of cells (Fig. 3a and g, Fig. 4d and g). Despite clear changes in cell morphology and orientation, no changes in the intensity of GAG or type II collagen staining were observed in these hypertrophic areas. RFP labelling indicated that human cells were only present within cartilaginous tissue and not in surrounding mineralized tissue. The ossified areas adjacent to two of the implants contained high levels of GAG and collagen type IIpositive tissue containing human cells, suggesting recent and ongoing ossification of the hESC-derived tissue by host cells (Fig. 4). While regions of human implanted tissue within the subchondral bone of some defects were undergoing a remodeling process, in others the implant remained well-integrated but stable (Fig. 4i-k). Native cartilage tissue directly adjacent to the implant contained proteoglycans and type II collagen despite clear boundaries between host and human cells indicating successful lateral integration at the articular surface. Using polarized light microscopy, collagen fibrils were found to be aligned perpendicular to the articular surface at the site of lateral integration (Fig. 4n) and in the nonsuperficial layer of some human tissue implants (Fig. 41), while fibrils were aligned in a parallel fashion at the articular surface (Fig. 41-m).

\section{Outcome assessments based on histological scoring}

Safranin O-stained sections of each defect were randomized and scored by three blinded reviewers using a modified ICRSII scoring system where 0 represents poor repair and 100 represents normal cartilage. The scores for each parameter for each defect were averaged and evaluated for statistical significance between implanted and control defects at both time points, and over time for each of the two treatments. Significant changes in 6 parameters were detected. Implanted defects had significantly higher scores in matrix staining and cell morphology at both 6 and 12 weeks compared to controls (Fig. 5b and c). The overall assessment, mid/deep zone assessment and integration with adjacent cartilage parameters were not significantly different between the defects receiving implants and controls after 6 weeks, but defects with human tissue scored significantly higher than controls at 12 weeks (Fig. 5a, d and e). The score for the degeneration of surrounding cartilage parameter was not significantly different between groups at ether time point observed. At 12 weeks the chondrocyte clustering parameter score was significantly higher in unimplanted defects than implanted (Fig. 5f). Over time, the scores for 


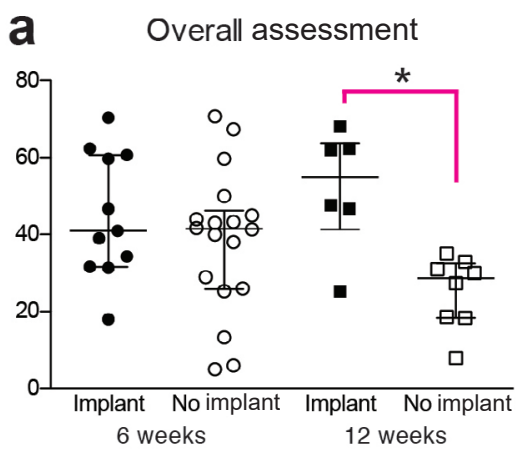

d

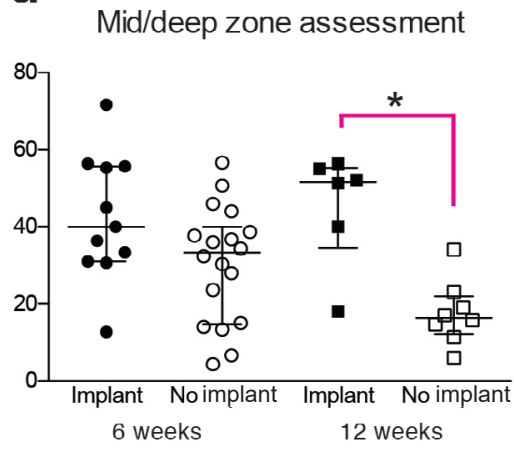

b

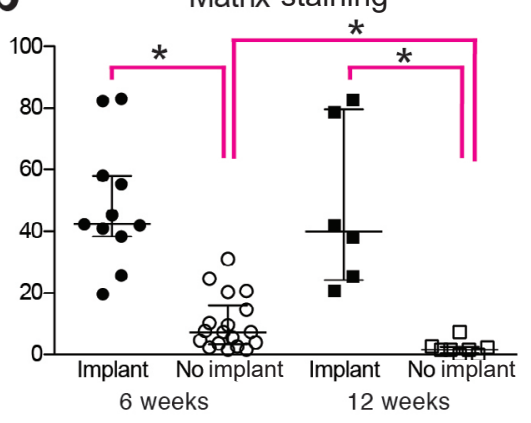

e

Integration with adjacent cartilage

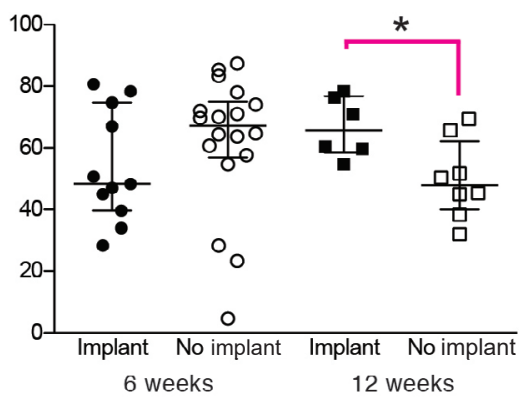

C

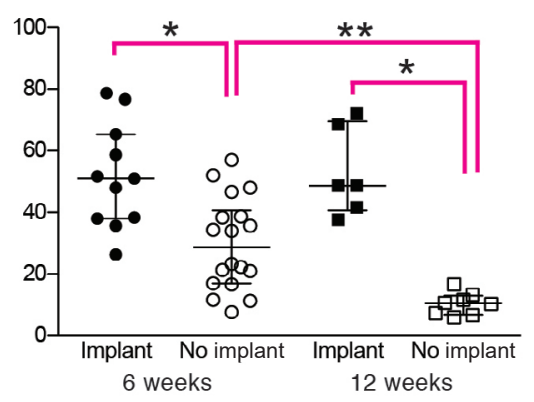

f

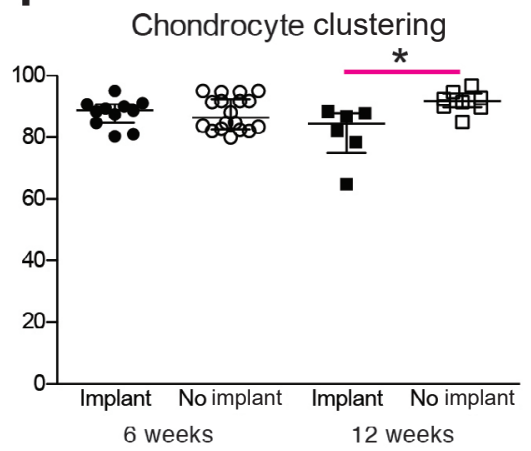

Fig. 5. Outcome assessments based on histological scoring demonstrate improved cartilage repair in defects implanted with hESC-derived articular cartilage. Defects were scored for cartilage quality parameters according to a modified ICRS II scoring system. Scores for each randomized defect were averaged from three blinded reviewers and plotted vertically according to treatment and time. Significant differences between treatment groups or over time were detected in scores for overall assessment (a), matrix staining (b), cell morphology (c), mid/deep zone assessment (d) and integration with adjacent cartilage (e) and chondrocyte clustering $(\mathbf{f})$. Averaged scores per defect are shown, the median value and interquartile range are indicated with horizontal lines. ${ }^{*} p<0.05,{ }^{* *} p<0.01$.

control defects significantly decreased in the matrix staining and cell morphology parameters (Fig. 5b and c) suggesting that the outcome of unimplanted defects worsened over time. There were no significant differences in the scores of implanted defects over time. Overall, these results indicate that cartilage repair quality was superior in defects receiving hESCderived implants compared to those receiving fibrin glue alone.

\section{Discussion}

Using the previously developed directeddifferentiation approach, it is possible to robustly and reproducibly generate articular chondrocytes and cartilage tissues from hESCs that resist hypertrophy and ossification over time following subcutaneous implantation in mice (Craft et al., 2015). This study aimed to further investigate the use hPSCs for cartilage repair by implanting hESC-derived cartilage tissue orthotopically, into osteochondral defects created in the rat trochlear groove.

At both 6 and 12 weeks after implantation, histological staining and immunohistochemical labelling showed that implanted tissues retained high levels of sulfated GAGs and type II collagen. This demonstrated the ability of hESC-derived tissues to maintain important articular cartilagelike characteristics within an articulating joint for at least 12 weeks. In contrast to defects that received implanted tissue, defects filled with fibrin glue alone contained mostly fibrous tissue after both 6 and 12 weeks. The generation of osteochondral defects that were filled with fibrin glue reflected some aspects of microfracture, the current standard of care in treating small- to medium-sized articular cartilage lesions in patients. It has been well established that the repair tissue following microfracture or drilling procedures is generally comprised of fibrocartilage (LaPrade et al., 2008). Although repair tissue found within control defects did contain low levels of type II collagen and in some cases sulfated GAGs, these matrix proteins were not consistently detected in all defects and their distribution was not homogeneous within the repair tissue. The significant difference in the composition of repair material was confirmed through histological scoring in which the implanted defects scored significantly higher in the 'matrix staining' parameter compared to controls. 
Defects implanted with human tissue showed high levels of basal and lateral integration with native tissue. The integrated boundaries between implanted and host tissue were mostly comprised of extracellular matrix, while human and rat cells remained clearly demarcated. Toh et al. previously reported a high degree of human-rat chimerism after hESC implantation into the rat knee (Toh et al., 2010). Our methods of analysis could not identify chimeric cells specifically, however, human and host cell populations were clearly discontinuous and no mixing of cell populations was observed in any of the defects after 6 or 12 weeks.

Despite the high level of integration of implanted tissues in this study, tissue delamination was observed in a number of defects, particularly at the 12-week time point. Implant fixation/immobilization remains to be a challenge surgically for chondral and osteochondral defects in the rat, as well as other animal models (Mumme et al., 2016b). Thus, the inherent risk of delamination was anticipated and accounted for in this study. Interestingly, an in-depth analysis of the rates of delamination revealed that proximal grafts were more likely to be affected than distal ones. The reason for this is unclear and, to the authors' knowledge, has not been previously reported. It is possible that increased rate of delamination was caused by differences in the mechanical forces applied to the proximal region versus the distal region; however, further investigations of this hypothesis were beyond the scope of this study.

The majority of implanted human tissues retained an articular cartilage-like matrix rich in GAGs and type II collagen, and lacking types I and X collagen. However, in several defects there was evidence of remodeling of the implanted tissue within subchondral bone regions. Implants at different stages of remodeling were found at both 6- and 12-week time points, suggesting that the process is triggered in different implants at different times and may not necessarily begin immediately after implantation. The location and changes in tissue composition and morphology suggest that remodeling was initiated in areas that were exposed to marrow cavities. Contact with the marrow may be analogous to the role of blood vessel invasion in the initiation of the endochondral ossification during development, or at the growth plate during long bone elongation. In areas of remodeling there were clear changes in the tissue structure (column formation) and morphology of the cells (hypertrophy) as well as changes in the matrix composition (increased collagen type $X$ ) that were reminiscent of endochondral ossification. Although these data to not definitively show that the process of remodeling is the same as the process endochondral ossification seen in development, or in the growth plate, the histological similarities between them are apparent.

The ability of hESC-derived chondrocytes to stimulate remodeling in subchondral bone regions warrants further investigation, with particular regard to the presence or absence of human cells within areas of newly formed bone. Through immunohistochemical labelling of human-cellexpressed RFP it was shown that implanted cells were found exclusively within cartilage-like tissue, and that the surrounding bone and marrow cavities were populated by host cells. In defects where remodeling was most advanced, areas of newly formed bone contained small regions of GAG and type II collagenpositive matrix which was surrounded by type I and type $X$ collagen-rich areas devoid of GAG staining. The enclosure of unusually high levels of GAG and type II collagen-rich matrix within bone tissue was indicative of de novo formation bone formation and was previously described in a similar model by Toh et al. (2010). The presence of RFP positive cells in the central, GAG-rich areas, but not in the adjacent surrounding bone suggested that the implanted human derived matrix was remodeled into bone by host cells, and that human cells did not actively contribute to new bone matrix production. No evidence of implanted chondrogenic cells transdifferentiating into osteoblasts was observed.

Previously published work on chondrocytes derived from hESCs using the same directeddifferentiation process demonstrated that these cells resisted hypertrophy in a subcutaneous implant model, rather than undergoing a remodeling process as seen in some implants in this study (Craft et al., 2015). One key difference between the two studies is the delivery method of the hESC-derived chondrocytes. The tissues implanted in this study consisted of preformed cartilaginous tissues, whilst those implanted previously were implanted at the same stage of differentiation, but as a single cell suspension within a biomaterial matrix. The results presented here show the importance of the cartilage matrix itself in remodeling and the subtle differences that may determine the stability of an implant in vivo. By further studying these processes it may be possible to improve cartilage repair in a number of ways. For example, the ability of the implant to integrate into the subchondral bone could result in protection against graft delamination and could improve the state of the subchondral bone itself, which is crucial for normal functions of articular cartilage (Imhof et al., 1999). This approach could effectively enable the treatment of osteochondral defects with a single cartilaginous hESC-derived implant.

A wide range of cell types are currently under investigation for use in cartilage repair, each with its own blend of advantages and disadvantages. MSCs provide a readily available source of cells that that can be harvested in a less invasive manner than chondrocytes, but they are hampered by their potential for terminal definition (Johnstone et al., 1998; Mueller et al., 2013; Pelttari et al., 2006). ACI and MACI, which utilize articular chondrocytes, have been used with clinical success, and nasal chondrocytes have shown promise in recently 
published in vivo studies (Brittberg, 2010; Brittberg et al., 1994; Mumme et al., 2016a; Mumme et al., 2016b). However, the use of articular or nasal chondrocytes requires multiple procedures to be performed and can result in donor site morbidity, increasing the risk to patients (although one-step procedures are being developed) (de Windt et al., 2017; Matricali et al., 2010). Human pluripotent stem cells provide alternatives to all of these issues, as a source of autologous, or perhaps allogeneic, cells that can be used to generate stable cartilage tissue in an offthe-shelf fashion. The work presented in this study demonstrates the capability of hESC-derived tissue to engraft and integrate within an osteochondral defect for up to 12 weeks. These data also show the potential for hESC-derived grafts to repair osteo as well as chondral regions of defects, providing a level of tissue regeneration that other cell types have not been shown to achieve.

\section{Conclusions}

In this report we demonstrate the ability of hESCderived articular cartilage tissues to engraft, persist and functionally integrate in an orthotopic site for up to 12 weeks. The results of this study support the notion that this is a viable approach for repairing damaged cartilage. Future studies will aim to improve the implantation of hPSC derived tissue, in order to better promote graft retention, and to investigate the potential of hESC-derived cartilage to repair both chondral and osteochondral defects with a single hESC-derived cartilage implant.

\section{Acknowledgements}

The authors would like to thank Benedikt Proffen and Johannes Konrad (Boston Children's Hospital) for histological scoring, Patricia E. Miller (Boston Children's Hospital) for statistical analyses, and the Center for Skeletal Research (P30AR066261) for histological expertise. This work was supported by an Accelerating Discoveries Research Award from the McEwen Centre for Regenerative Medicine, the Arthritis Program at Toronto Western Research Institute, and a generous gift from the Krembil Foundation.

\section{References}

Akabayashi A, Nakazawa E, Jecker NS (2019) The world's first clinical trial for an aplastic anemia patient with thrombocytopenia administering platelets generated from autologous iPS cells. Int J Hematol 109: 239-240.

Benjamini Y, Hochberg Y (1995) Controlling the false discovery rate: a practical and powerful approach to multiple testing. J R Statist Soc B 57: 289-300.

Benya PD, Shaffer JD (1982) Dedifferentiated chondrocytes reexpress the differentiated collagen phenotype when cultured in agarose gels. Cell 30: 215-224.

Brittberg M (2010) Cell carriers as the next generation of cell therapy for cartilage repair: a review of the matrix-induced autologous chondrocyte implantation procedure. Am J Sports Med 38: 12591271.

Brittberg M, Lindahl A, Nilsson A, Ohlsson C, Isaksson O, Peterson L (1994) Treatment of deep cartilage defects in the knee with autologous chondrocyte transplantation. N Engl J Med 331: 889895.

Craft AM, Ahmed N, Rockel JS, Baht GS, Alman BA, Kandel RA, Grigoriadis AE, Keller GM (2013) Specification of chondrocytes and cartilage tissues from embryonic stem cells. Development 140: 25972610.

Craft AM, Rockel JS, Nartiss Y, Kandel RA, Alman BA, Keller GM (2015) Generation of articular chondrocytes from human pluripotent stem cells. Nat Biotechnol 33: 638-645.

De Bari C, Dell'Accio F, Luyten FP (2001a) Human periosteum-derived cells maintain phenotypic stability and chondrogenic potential throughout expansion regardless of donor age. Arthritis Rheum 44: 85-95.

De Bari C, Dell'Accio F, Tylzanowski P, Luyten FP (2001b) Multipotent mesenchymal stem cells from adult human synovial membrane. Arthritis Rheum 44: 1928-1942.

de Windt TS, Vonk LA, Slaper-Cortenbach IC, van den Broek MP, Nizak R, van Rijen MH, de Weger RA, Dhert WJ, Saris DB (2017) Allogeneic mesenchymal stem cells stimulate cartilage regeneration and are safe for single-stage cartilage repair in humans upon mixture with recycled autologous chondrons. Stem Cells 35: 256-264.

Dowthwaite GP, Bishop JC, Redman SN, Khan IM, Rooney P, Evans DJ, Haughton L, Bayram Z, Boyer S, Thomson B, Wolfe MS, Archer CW (2004) The surface of articular cartilage contains a progenitor cell population. J Cell Sci 117: 889-897.

Holtzer H, Abbott J, Lash J, Holtzer S (1960) The loss of phenotypic traits by differentiated cells in vitro, I. Dedifferentiation of cartilage cells. Proc Natl Acad Sci U S A 46: 1533-1542.

Ilic D, Devito L, Miere C, Codognotto S (2015) Human embryonic and induced pluripotent stem cells in clinical trials. Br Med Bull 116: 19-27.

Imhof H, Breitenseher M, Kainberger F, Rand T, Trattnig S (1999) Importance of subchondral bone to articular cartilage in health and disease. Top Magn Reson Imaging 10: 180-192.

Irion S, Luche H, Gadue P, Fehling HJ, Kennedy M, Keller G (2007) Identification and targeting of the ROSA26 locus in human embryonic stem cells. Nat Biotechnol 25: 1477-1482. 
Johnstone B, Hering TM, Caplan AI, Goldberg VM, Yoo JU (1998) In vitro chondrogenesis of bone marrow-derived mesenchymal progenitor cells. Exp Cell Res 238: 265-272.

Kobayashi S, Takebe T, Zheng YW, Mizuno M, Yabuki Y, Maegawa J, Taniguchi H (2011) Presence of cartilage stem/progenitor cells in adult mice auricular perichondrium. PLoS One 6: e26393.

LaPrade RF, Botker JC (2004) Donor-site morbidity after osteochondral autograft transfer procedures. Arthroscopy 20: e69-73.

LaPrade RF, Bursch LS, Olson EJ, Havlas V, Carlson CS (2008) Histologic and immunohistochemical characteristics of failed articular cartilage resurfacing procedures for osteochondritis of the knee: a case series. Am J Sports Med 36: 360-368.

Levato R, Webb WR, Otto IA, Mensinga A, Zhang Y, van Rijen M, van Weeren R, Khan IM, Malda $\mathrm{J}$ (2017) The bio in the ink: cartilage regeneration with bioprintable hydrogels and articular cartilagederived progenitor cells. Acta Biomater 61: 41-53.

Mainil-Varlet P, Van Damme B, Nesic D, Knutsen G, Kandel R, Roberts S (2010) A new histology scoring system for the assessment of the quality of human cartilage repair: ICRS II. Am J Sports Med 38: 880-890.

Matricali GA, Dereymaeker GP, Luyten FP (2010) Donor site morbidity after articular cartilage repair procedures: a review. Acta Orthop Belg 76: 669-674.

McCarthy HE, Bara JJ, Brakspear K, Singhrao SK, Archer CW (2012) The comparison of equine articular cartilage progenitor cells and bone marrow-derived stromal cells as potential cell sources for cartilage repair in the horse. Vet J 192: 345-351.

Mueller MB, Fischer M, Zellner J, Berner A, Dienstknecht T, Kujat R, Prantl L, Nerlich M, Tuan RS, Angele P (2013) Effect of parathyroid hormonerelated protein in an in vitro hypertrophy model for mesenchymal stem cell chondrogenesis. Int Orthop 37: 945-951.

Mumme M, Barbero A, Miot S, Wixmerten A, Feliciano S, Wolf F, Asnaghi AM, Baumhoer D, Bieri O, Kretzschmar M, Pagenstert G, Haug M, Schaefer DJ, Martin I, Jakob M (2016a) Nasal chondrocytebased engineered autologous cartilage tissue for repair of articular cartilage defects: an observational first-in-human trial. Lancet 388: 1985-1994.

Mumme M, Steinitz A, Nuss KM, Klein K, Feliciano S, Kronen P, Jakob M, von Rechenberg B, Martin I, Barbero A, Pelttari K (2016b) Regenerative potential of tissue-engineered nasal chondrocytes in goat articular cartilage defects. Tissue Eng Part A 22: 1286-1295.

Pelttari K, Pippenger B, Mumme M, Feliciano S, Scotti C, Mainil-Varlet P, Procino A, von Rechenberg B, Schwamborn T, Jakob M, Cillo C, Barbero A, Martin I (2014) Adult human neural crest-derived cells for articular cartilage repair. Sci Transl Med 6: 251ra119.

Pelttari K, Winter A, Steck E, Goetzke K, Hennig T, Ochs BG, Aigner T, Richter W (2006) Premature induction of hypertrophy during in vitro chondrogenesis of human mesenchymal stem cells correlates with calcification and vascular invasion after ectopic transplantation in SCID mice. Arthritis Rheum 54: 3254-3266.

Pittenger MF, Mackay AM, Beck SC, Jaiswal RK, Douglas R, Mosca JD, Moorman MA, Simonetti DW, Craig S, Marshak DR (1999) Multilineage potential of adult human mesenchymal stem cells. Science 284: 143-147.

Redman SN, Oldfield SF, Archer CW (2005) Current strategies for articular cartilage repair. Eur Cell Mater 9: 23-32.

Staerk J, Dawlaty MM, Gao Q, Maetzel D, Hanna J, Sommer CA, Mostoslavsky G, Jaenisch R (2010) Reprogramming of human peripheral blood cells to induced pluripotent stem cells. Cell Stem Cell 7: 2024.

Steadman JR, Rodkey WG, Rodrigo JJ (2001) Microfracture: surgical technique and rehabilitation to treat chondral defects. Clin Orthop Relat Res 391 Suppl: S362-369.

Stoddart MJ, Richards RG, Alini M (2012) In vitro experiments with primary mammalian cells: to pool or not to pool? Eur Cell Mater 24: i-ii.

Takahashi K, Tanabe K, Ohnuki M, Narita M, Ichisaka T, Tomoda K, Yamanaka S (2007) Induction of pluripotent stem cells from adult human fibroblasts by defined factors. Cell 131: 861-872.

Toh WS, Lee EH, Guo XM, Chan JK, Yeow $\mathrm{CH}$, Choo AB, Cao $\mathrm{T}$ (2010) Cartilage repair using hyaluronan hydrogel-encapsulated human embryonic stem cell-derived chondrogenic cells. Biomaterials 31: 6968-6980.

von der Mark K, Gauss V, von der Mark H, Muller P (1977) Relationship between cell shape and type of collagen synthesised as chondrocytes lose their cartilage phenotype in culture. Nature 267: 531-532.

Williams R, Khan IM, Richardson K, Nelson L, McCarthy HE, Analbelsi T, Singhrao SK, Dowthwaite GP, Jones RE, Baird DM, Lewis H, Roberts S, Shaw HM, Dudhia J, Fairclough J, Briggs T, Archer CW (2010) Identification and clonal characterisation of a progenitor cell sub-population in normal human articular cartilage. PLoS One 5: e13246.

Zuk PA, Zhu M, Ashjian P, De Ugarte DA, Huang JI, Mizuno H, Alfonso ZC, Fraser JK, Benhaim P, Hedrick MH (2002) Human adipose tissue is a source of multipotent stem cells. Mol Biol Cell 13: 4279-4295.

\section{Discussion with Reviewers}

Paola Occhetta: With reference to the process of biopsy punching ESC derived cartilage, it is known that mechanical disruption of cartilage tissue induces changes in key genes required for cartilage homeostasis, such as FGFR3. Did the authors consider this when designing this experimental approach and whether this would negatively influence cartilage repair?

Authors: Damage of any sort, even with a surgical instrument like a biopsy punch, is likely to lead to 
changes in gene expression and protein production. By definition, a defect site is not likely to be an optimal place for implantation, even if surgically prepared. However, during the preparation of a defect for the implantation of a construct in ACI/ $\mathrm{MACI}$, or even during microfracture, the edges of the defect are debrided with a curette. As the use of a biopsy punch is likely to have a similar effect on the surrounding cartilage, the authors hypothesized that any effect, negative or positive, would reflect what a construct would see in a 'real world' situation. In order for new cell-based therapies for cartilage repair to be successfully translated into the clinic, it will be important to better understand the relationship between the implant and the surrounding tissue as it may be the key not only to successful retention but also reduced degeneration of surrounding tissue. Future studies in large animal are aimed to address this.

Paola Occhetta: The authors state that collagen type I was present at the edge of tissues in host derived fibrous tissues that covered the majority of implants. Is this likely to be a form of foreign body reaction? Was there any evidence of macrophage infiltration? Authors: The fibrous tissue at the surface of the implants contains type I collagen and, in some cases, also contains proteoglycans and type II collagen. The authors found no evidence of macrophage-derived cells within this fibrous tissue adjacent, suggesting that is not part of a foreign body response.

Paola Occhetta: It is clear from the images provided that there has been some level of proteoglycan loss at the site directly adjacent to the implant, is this seen in all implanted knees and does it recover?

Authors: The degeneration of the surrounding cartilage was addressed in the scoring but there was no significant difference between the groups. What is of note is that although GAG content may be reduced in the surrounding tissue, type II collagen remained present. The combined role of GAG and collagen type II in the maintenance of joint surface integrity is not fully understood, but the presence and apparent integration of collagen networks should be protective of joint surface integrity.

Scott Roberts: Results of in vivo implantation convincingly showed the ability of hESC-derived tissues to better maintain articular cartilage-like characteristics as compared to implanted tissue that resulted in mostly fibrous tissue. The only point which is not fully addressed is in my opinion the presence of collagen type- $X$ positive staining in some of the constructs. The author claimed that collagen type- $X$ staining was found in 5/11 constructs at 6 weeks, but they don't investigate the possible reason for these drastic differences in outcome. Is it possible that different results are related to an intrinsic variability of the cells or to a different outcome at the end of the in vitro differentiation stage due to variability of the production? If this is not the case, a deeper investigation over the possible causes should be included and discussed, considering that 5/11 define a variability of almost $50 \%$. Moreover, this parameter should be quantified and possibly included in the quantitative assessments of Fig. 5, to give a complete overview of the results.

Authors: This is an important point and has been the subject of discussion between the authors. Histological and gene-expression analysis performed over a period of years on innumerable cartilage tissues produced from the HES2 hPSC cell line and others using the method described here showed little variation between constructs at a gene expression or protein level (Craft et al. 2015). As a result, the authors feel that the variation seen is likely not to come from the implanted cells but from the environment they are implanted into. Histological observation shows that remodeling/collagen $X$ expression initiation occurs at a point where the construct is exposed to the marrow cavity, suggesting, as discussed, that the cells within the marrow play a role in this process (and therefore so does the degree of graft exposure to the marrow). Using a semi-quantitative scoring system, devised by the authors, positive correlation was found between the amount of remodeling, collagen type $X$ expression and the degree of exposure of the construct to the marrow cavity. Although this further supports the role of the cells in the marrow cavity, this immunohistochemistry-based scoring is not, in the authors' opinion, sufficient to provide conclusive evidence that this is the only factor influencing this phenomenon. Due to the limited number of samples remaining from this study it is not possible to provide a mechanistic explanation of this process. Further work is underway to properly investigate the initiation and propagation of the terminal differentiation that was described in this model.

Editor's note: The Scientific Editor responsible for this paper was Martin Stoddart. 